\title{
EMR implementation of default opioid prescription quantities
}

\author{
Brandon M. Theriault, BA ', Christina F. Burger, Pharm D, BCPS, BCGP2, and Joseph J. Schlesinger, \\ $M D^{\prime}$
}

'Department of Anesthesiology, Vanderbilt University Medical Center, Nashville, TN, USA; ${ }^{2}$ VA Tennessee Valley Healthcare System, Nashville, TN, USA.

J Gen Intern Med 33(11): 1827

DOI: $10.1007 / \mathrm{s} 11606-018-4604-6$

(C) Society of General Internal Medicine 2018

$I^{\prime \prime}$ $\mathrm{n}$ an attempt to curb the opioid epidemic currently plaguing America, Arizona lawmakers have recently signed legislation limiting initial opioid prescriptions to 5 days and setting a maximum prescription duration of 30 days for certain patients receiving opioids. ${ }^{1}$ While the goal of this controversial legislation is to curb opioid abuse by legally limiting the quantities of opioids prescribed, one can envision that a potential negative sequelae to this approach is restricting access for patients in which opioid therapy is medically indicated. Incorporation of EMR default opioid quantities to influence prescribing behavior was, in a review of previous literature, shown to significantly affect emergency room physician prescribing behavior, though limited success was observed by Delgado et al. for various hypothesized reasons. ${ }^{2}$ The use of EMR systems as tools to address long-term opioid therapy (LTOT) prescription rates may have a more expansive impact on the current epidemic than interventions in emergency department EMRs alone. With approximately 3 to $4 \%$ of the adult US population being prescribed LTOT, this type of pain treatment is a continual source of opioid prescriptions for many patients. ${ }^{3}$ As nearly all hospitals have adopted electronic medical records (EMR) for patient care, the implementation of default opioid prescription options, ${ }^{2}$ in conjunction with queries for physicians deviating from standard practices or electronic alerts on patients at risk for opioid abuse, ${ }^{4}$ presents an expansive opportunity to influence the prescribing behavior of physicians on a consistent basis. Further research is needed to assess the potential effects of EMR default implementation in other areas where patients receive greater quantities of opioids. Continued changes in laws are likely to require improved use of prescription drug monitoring programs (PDMPs) across the country which would work to address other common sources

Published online July 27, 2018 of opioid diversion such as doctor shopping. ${ }^{5}$ Better integration of PDMPs into EMR systems is believed to be another tool which could prove useful in preventing opioid abuse. ${ }^{5}$ In contrast to the legislation recently approved in Arizona, maximal utilization of the EMR encourages physicians to limit opioid prescribing without legally limiting their authority to do so. Additionally, it is unclear whether legislation such as that passed in Arizona will significantly attenuate the statewide overdose rate. Regardless of whether similar legislation is passed on a national level, individual hospitals should consider utilizing EMR implementation to address low confidence levels related to opioid prescriptions and properly guide physicians as they navigate the challenges associated with pain management. ${ }^{5}$

Corresponding Author: Brandon M. Theriault, BA; Department of Anesthesiology Vanderbilt University Medical Center, Nashville, TN, USA (e-mail: Brandon.M.Theriault@Vanderbilt.edu).

\section{Compliance with ethical standards:}

Conflict of interest: Please provide Conflict of Interest statement for this article.

\section{REFERENCES}

1. Reuters. Arizona governor signs opioid crackdown legislation. Available at: https://www.reuters.com/article/us-arizona-opiods/arizona-governorsigns-opioid-crackdown-legislation-idUSKBN1FF2O6. Accessed February 7, 2018.

2. Delgado MK, Shofer FS, Patel MS, et al. Association between Electronic Medical Record Implementation of Default Opioid Prescription Quantities and Prescribing Behavior in Two Emergency Departments. J Gen Intern Med, 2018; https://doi.org/10.1007/s11606-017-4286-5.

3. Dowell D, Haegerich TM, Chou R. CDC guideline for prescribing opioids for chronic pain-United States, 2016. JAMA. 2016; 315(15), 1624-1645.

4. Malte CA, Berger D, Saxon AJ, et al. Electronic Medical Record Alert Associated With Reduced Opioid and Benzodiazepine Coprescribing in High-risk Veteran Patients. Med Care. 2018; 56(2), 171-178.

5. Volkow ND, McLellan AT. Opioid abuse in chronic pain-misconceptions and mitigation strategies. N Engl J Med. 2016; 374(13), 1253-1263. 